\title{
Molecular imaging in heart failure patients
}

\author{
Nagara Tamaki $\cdot$ Yuji Kuge $\cdot$ Keiichiro Yoshinaga
}

Received: 20 May 2013/Accepted: 5 September 2013/Published online: 9 October 2013

(C) The Author(s) 2013. This article is published with open access at Springerlink.com

\begin{abstract}
This review focuses on molecular imaging using various radioligands for the tissue characterization of patients with heart failure. ${ }^{123}$ I-labeled metaiodobenzylguanidine (MIBG), as a marker of adrenergic neuron function, plays an important role in risk stratification in heart failure and may be useful for predicting fatal arrhythmias that may require implantable cardioverter-defibrillator treatment. MIBG has also been used for monitoring treatment effects under various medications. Various positron emission tomography (PET) radioligands have been introduced for the quantitative assessment of presynaptic and postsynaptic neuronal function in vivo. ${ }^{11} \mathrm{C}$-hydroxyephedrine, like MIBG, has potential for assessing the severity of heart failure. Our PET study using the $\beta$-receptor antagonist ${ }^{11} \mathrm{C}$-CGP 12177 in patients with heart failure showed a reduction of $\beta$-receptor density, indicating downregulation, in most of the patients. More studies are needed to confirm the clinical utility of these molecular imaging modalities for the management of heart failure patients.
\end{abstract}

Keywords Radionuclide imaging · Positron emission tomography $\cdot$ Molecular imaging $\cdot$ Heart failure $\cdot$ Adrenergic neuronal imaging $\cdot$ Receptor imaging

Color figures online at http://link.springer.com/article/10.1007/s403 36-013-0034-y.

N. Tamaki $(\bowtie) \cdot$ K. Yoshinaga

Department of Nuclear Medicine, Graduate School of Medicine, Hokkaido University, N-15, W-7, Kita-ku, Sapporo 060-8538, Japan

e-mail: natamaki@med.hokudai.ac.jp

Y. Kuge

Central Institute of Isotope Science, Hokkaido University,

Sapporo, Japan

\section{Introduction}

Heart failure is a major cause of mortality and morbidity. The treatment of heart failure patients has been found to entail tremendous medical costs in many countries $[1,2]$. Although heart failure treatment has improved greatly, the 5 -year mortality rate continues to be $40-50 \%[2,3]$. Myocardial infarction (MI) is recognized as a prime cause of systolic heart failure $[4,5]$. An acute MI will result in changes in left ventricular (LV) size, shape, and wall thickness that involve the infarcted and non-infarcted regions; these changes are referred to as "LV remodeling" [6-9]. Various myocardial disorders, including dilated cardiomyopathy, also cause severe LV dilatation with heart failure.

A number of non-invasive cardiovascular imaging modalities are currently used to assess the severity of heart failure. Among them, molecular imaging has recently been a focus of interest on account of its ability to characterize tissues involved in myocardial disorders at different levels: molecular, subcellular, and cellular [10-12]. Molecular imaging promises to not only deepen our understanding of already known biological processes, but also to uncover unknown molecular and cellular events that are at the center of the initiation and evolution of disease. Compared to traditional in vitro tissue/cell culture and ex vivo animal studies, molecular imaging permits the non-invasive and repetitive imaging of targeted biological processes at both cellular and subcellular levels in live organs. Molecular imaging thus offers a means to visualize specific abnormal biological processes for diagnosis and treatment.

Radionuclide imaging, using either positron emission tomography (PET) or single-photon emission computed tomography (SPECT), has been the modality most commonly used for human molecular imaging, mainly due to 
its quite high sensitivity to radiolabeled ligands with nanoor micro-order levels compared to other methods of molecular imaging. Even though molecular imaging has low spatial and temporal resolutions and high background activity and radiation, radionuclide imaging has been safely used in a wide range of clinical applications, including evaluations of various disease processes.

\section{Imaging autonomic functions}

As a result of advances in vivo biochemical imaging using radionuclide techniques, the modulation of functional and electrophysiological properties of the heart by the autonomic nervous system has become a focus of interest in the field of cardiovascular research. Cardiac neuronal function is compromised in various cardiac diseases, including congestive heart failure, ischemia, arrhythmia, and some types of cardiomyopathy [13]. Tracer approaches are considered uniquely suited for radionuclide imaging-based in vivo characterization of neuronal function in the myocardium.

The autonomic nervous system consists of two main parts: sympathetic and parasympathetic innervations. Their major transmitters are norepinephrine and acetylcholine, respectively, which define the stimulatory and inhibitory physiological effects of each system. Sympathetic innervation originates mainly from the right and left stellate ganglia, which provide the sympathetic nerves to form the cardiac plexus of the heart. The sympathetic nerve fibers travel parallel to the vascular structures on the epicardial surface of the heart and then penetrate the underlying myocardium in a manner similar to that seen in the coronary vessels [14]. As regard to tissue levels of norepinephrine, the mammalian heart is characterized by dense adrenergic innervation with a norepinephrine concentration gradient from the atria to the base of the heart and from the base to the apex of the left ventricle $[15,16]$.
Parasympathetic innervation, by contrast, originates from the medulla and passes through the right and left vagal nerves, which further divide into the superior and inferior cardiac nerves. Parasympathetic nerve fibers primarily modulate sinoatrial nodal and atrioventricular nodal function and innervate the atria, whereas, vagal fibers to the ventricles are rather sparse [17]. These autonomic nervous systems are involved in the synthesis and storage of neurotransmitters and their release, reuptake, metabolism, and interaction with presynaptic and postsynaptic receptor sites.

There are a number of radiotracers that can be used to probe each step of autonomic neuronal functions. Table 1 shows representative radiotracers used to probe sympathetic and parasympathetic nerve functions, both presynaptic and postsynaptic. Figure 1 illustrates a number of adrenergic presynaptic and postsynaptic (receptor) functions, indicating the radiopharmaceuticals that have been used to probe those functions. For example, Eisenhoffer et al. [18-20] used radiolabeled norepinephrine for the assessment of sympathetic nerve function and norepinephrine kinetics.

Among these radiopharmaceuticals, the norepinephrine analog metaiodobenzylguanidine (MIBG) has been widely used in experimental and clinical studies for sympathetic nerve imaging. In the early 1980s, University of Michigan researchers developed ${ }^{131} \mathrm{I}$ MIBG as a norepinephrine analog for the selective mapping of sympathetic nerve endings in the heart $[21,22] .{ }^{123}$ I-labeled MIBG is now commonly used for cardiac imaging.

\section{Fundamental aspects of ${ }^{123}$ I-labeled MIBG}

MIBG is an analog of the antihypertensive drug guanethidine and of norepinephrine itself. It is taken up by sympathetic nerves in a similar manner to norepinephrine, but is not metabolized. Most MIBG, following its administration, is actively taken up into neuronal vesicles by means of
Table 1 Radiotracers used for the evaluation of autonomic nervous system functions

\begin{tabular}{lll}
\hline & Sympathetic nerves & Parasympathetic nerves \\
\hline Presynaptic & ${ }^{123}$ I-metaiodobenzylguanidine (MIBG) & ${ }^{123}$ I-iodobenzoversamicol \\
& ${ }^{11} \mathrm{C}$-hydroxyephedrine & \\
& ${ }^{18} \mathrm{~F}$-metaraminol & \\
& ${ }^{18} \mathrm{~F}$-dopamine & \\
& ${ }^{11} \mathrm{C}$-threohydroxyepinephrine & \\
Postsynaptic & ${ }^{11} \mathrm{C}$-epinephrine & ${ }^{123}$ I-quinuclidinyl benzylate (QNB) \\
& ${ }^{\text {I1 }}$-iodocyanopindolol (ICYP) & \\
& ${ }^{11} \mathrm{C}$-practolol & \\
& ${ }^{11} \mathrm{C}$-propranolol & \\
& ${ }^{11} \mathrm{C}$-CGP C-prazocin 12177 & \\
\hline
\end{tabular}


Fig. 1 Schema of myocardial nerve terminals and various radioligands used to probe adrenergic functions (Color figure online)

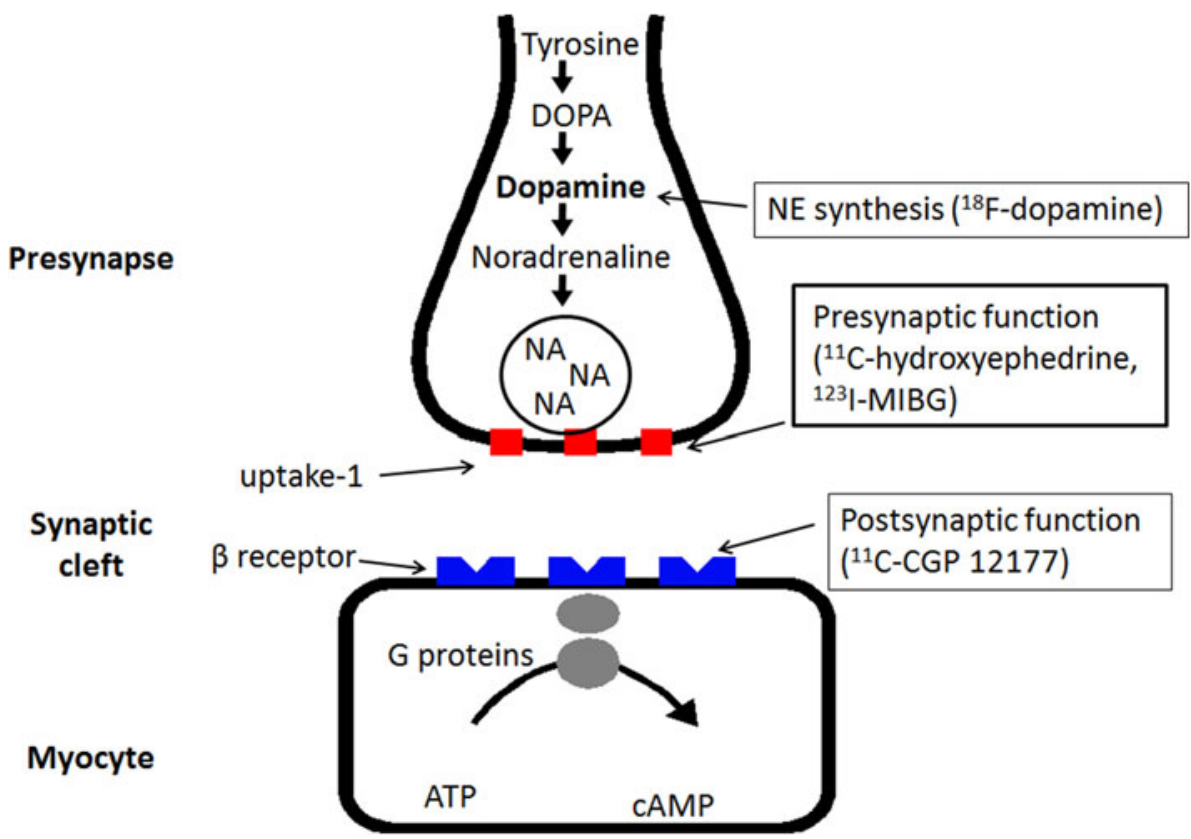

a Na-dependent specific process (uptake 1), and the remaining MIBG enters the nerve terminals by passive diffusion (uptake 2) [23, 24]. Although uptake 1 accounts for most MIBG distribution in the myocardium, uptake 2 may play a minor role $[25,26]$. MIBG is stored by the neurons and is released along with endogenous norepinephrine upon nerve stimulation, but it has a low affinity for postsynaptic adrenergic receptors. Generally, MIBG distribution correlates with that of tissue norepinephrine, but the ability of sympathetic nerve terminals to take up catecholamine is a more sensitive index of nerve function and viability than catecholamine content [27]. Based on the mechanisms of uptake of this SPECT agent, it is recommended to temporarily discontinue medications and substrates that may interfere with norepinephrine uptake, including opioids, antidepressants, reserpine, and others [28].

${ }^{123}$ I-labeled MIBG is used in clinical settings, as it provides better myocardial images than the ${ }^{131}$ I-labeled compound. A clinical study showed that increased sympathetic tone may be associated with increased washout of MIBG [23, 29]. Following the administration of 111-222 MBq (3-6 mCi) of ${ }^{123}$ I-labeled MIBG at rest, myocardial images are usually obtained twice (at $10 \mathrm{~min}$ and $4 \mathrm{~h}$ ) to calculate the myocardial uptake and washout. Sometimes only the delayed images are obtained to estimate delayed myocardial uptake as an index of adrenergic neuron function. In each acquisition, the planar images are obtained in the anterior position to assess the global uptake of MIBG in the myocardium. SPECT imaging can also be added to assess the regional MIBG distribution. The general acquisition time is $3-5$ min for planar imaging and 15-30 min for SPECT imaging. A suitable collimator (either a medium-energy collimator or a ${ }^{123} \mathrm{I}$ collimator) should be used for ${ }^{123} \mathrm{I}$ imaging. Some low-energy collimators are also suitable for ${ }^{123} \mathrm{I}$ energy, showing higher sensitivity than medium-energy collimators. Resting administration is most commonly used for the resting state $[28,30]$.

The radiation dose with the use of $111 \mathrm{MBq}$ of MIBG is $1.2 \mathrm{mGy}$ to the myocardium and $7.9 \mathrm{mGy}$ to the liver. To minimize radiation to the thyroid gland, thyroid blocking is recommended.

Although ${ }^{123}$ I-labeled MIBG yields high-quality images of myocardial neuronal function, high activity in the liver may be superimposed on myocardial activity in planar images, and thus affect the interpretation of myocardial distribution, particularly in the inferior region. To minimize such superimposition, SPECT is preferred for the assessment of regional MIBG distribution. Planar imaging is used to assess the global uptake of the tracer in the myocardium. Two regions of interest are considered: an irregular region in the whole myocardium and a rectangular region in the upper mediastinum to measure the myocardium-to-mediastinum count rate, which is commonly used as an index of myocardial uptake of MIBG (Fig. 2) [28, 30]. A semi-automatic algorithm for calculating the heart-to-mediastinum (H/M) ratio on MIBG imaging was recently introduced to obtain highly reproducible values [31]. However, there is no established SPECT-based method for estimating or scoring MIBG uptake.

In reports concerning imaging standards and a relevant Japanese database, the normal myocardium-to-mediastinum count rate ranged from 2.0 to 2.7 for the early scan and from 2.1 to 2.9 for the late scan [32, 33], but these values seemed to be dependent on the collimator used for 


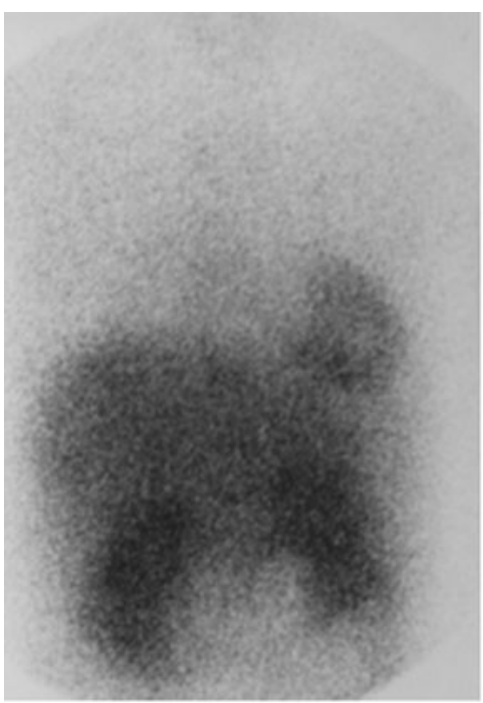

$H / M=2.2$

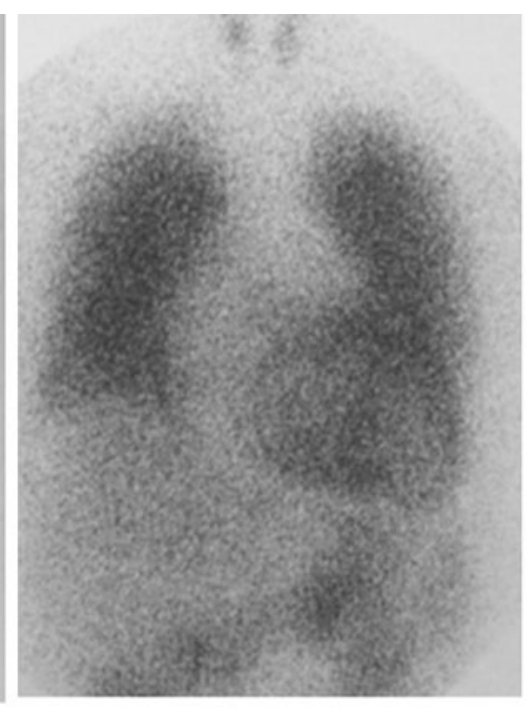

$H / M=1.6$

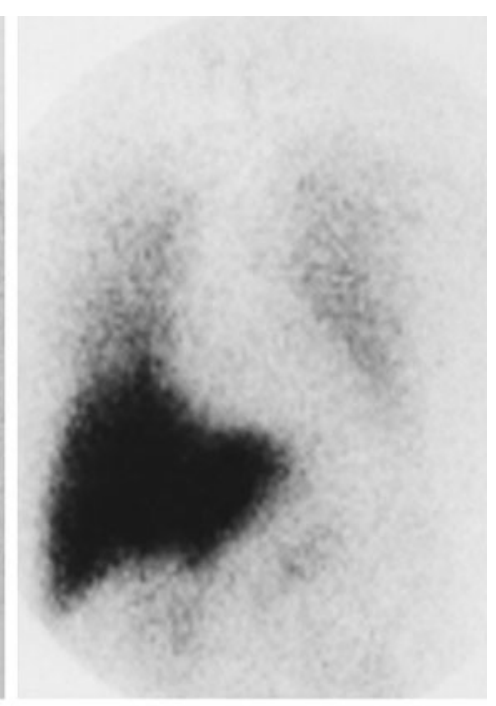

$H / M=1.2$

Fig. 2 Anterior images at $4 \mathrm{~h}$ after ${ }^{123}$ I-labeled MIBG administration in a normal control (left), a patient with moderate (middle), and a patient with severe heart failure (right). The heart-to-mediastinal count ratio $(\mathrm{H} / \mathrm{M})$ is a marker of MIBG uptake in the heart

acquisition and the specific activity of the MIBG. Nakajima and colleagues, using different energy collimators, recently developed a calibration phantom as a tool for standardizing MIBG H/M ratio calculation for a normal-values database [34]. This method may be practical for multicenter studies. The washout from the early to the late scan ranged from 21 to $33 \%$.

In a 1993 clinical study, the normal distribution of MIBG in the myocardium was not quite homogeneous, showing a slight reduction in the inferior region [35]. This heterogeneity seems to be more enhanced with age [36]. In view of this physiological heterogeneity of the tracer distribution in the myocardium, MIBG images should be interpreted cautiously.

\section{Clinical aspects of ${ }^{123}$ I-labeled MIBG}

It is well-known that adrenergic dysfunction plays a key role in heart failure, and the plasma catecholamine level has been recognized as a valuable prognostic tool. Basic studies have indicated that an increased neuronal release of norepinephrine and decreased efficiency of norepinephrine reuptake both contribute to increased cardiac adrenergic drive in congestive heart failure [20]. In addition, decreased vesicular leakage of norepinephrine limits the increase in its cardiac turnover. Thus, analyses of norepinephrine kinetics have a key role in the assessment of the severity of congestive heart failure.

There are a number of reports showing a reduction of MIBG retention in patients with idiopathic dilated cardiomyopathy [37-40]. Schoffer et al. [37] first indicated that the $\mathrm{H} / \mathrm{M}$ ratio for MIBG is correlated with the plasma norepinephrine level and the left ventricular ejection fraction (LVEF) in patients with dilated cardiomyopathy. Their MIBG results showed that uptake and vesicular storage of norepinephrine were reduced in these patients, similar to the findings in experimental heart failure.

MIBG imaging has long been applied in patients with heart failure in general. A number of papers have highlighted the $\mathrm{H} / \mathrm{M}$ ratio and/or the washout rate of MIBG as new parameters of heart failure severity and independent prognostic indicators [41-50]. Merlet et al. [41], in 1999, were the first to indicate the prognostic value of the $\mathrm{H} / \mathrm{M}$ ratio in patients with heart failure. Thereafter, many prognostic studies using this imaging technique were performed in European countries and in Japan; there thus emerged a close association between the $\mathrm{H} / \mathrm{M}$ ratio and/or the washout rate of MIBG as markers of impaired cardiac adrenergic innervation and mortality in patients with heart failure [41-50]. A meta-analysis of 18 studies including 1,755 patients with heart failure confirmed that heart failure patients showing a reduced $\mathrm{H} / \mathrm{M}$ ratio on late MIBG imaging had a worse prognosis as compared to those with a normal $\mathrm{H} / \mathrm{M}$ ratio [51]. A similar meta-analysis was reported from Japan, indicating that both decreased MIBG uptake and its increased washout are indicative of a poor prognosis in heart failure patients [52].

Sudden cardiac death due to fatal arrhythmia is a major healthcare problem. Implantable cardioverter-defibrillator (ICD) treatment has become well established for preventive use in patients at high risk of arrhythmic death. Autonomic dysfunction assessed by MIBG is thought to play an important role in the detection of high-risk ventricular arrhythmia $[14,53,54]$. In particular, MIBG can 
identify areas of denervation hypersensitivity which may be likely to cause ventricular arrhythmias. A number of pilot studies have indicated MIBG as a potential predictor of ventricular arrhythmias in patients with an ICD [55-60].

Nishisato et al. [57], in a prospective study using both MIBG and resting myocardial perfusion imaging in patients who received ICD treatment, showed that ICD discharge was documented in 30 of the total 60 patients $(50 \%)$. They reported that among the various clinical and scintigraphic variables, low $\mathrm{H} / \mathrm{M}$ ratio on MIBG and a large perfusion defect were the most powerful predictors of ICD discharge in a Cox multivariate analysis. This report was the first to suggest an incremental benefit for the assessment of sympathetic nerve function in combination with myocardial perfusion, and a role for this combined assessment in the risk stratification of patients who may need prophylactic ICD therapy. Both denervation and myocardial scar were important predictors of ICD discharge and fatal arrhythmias. However, it remains unknown whether simple perfusion imaging is enough, or whether both MIBG and perfusion imaging are required to predict such fatal arrhythmias. These authors provided consistent findings showing that ${ }^{123}$ I-labeled MIBG may predict ICD discharge and sudden cardiac death independently of conventional parameters.

Tamaki et al. [61] examined the ability of MIBG imaging to predict sudden cardiac death in comparison with ECG parameters such as T-wave alteration. They found that the MIBG washout rate was independent of LVEF in risk analyses of patients with heart failure. A multivariate Cox analysis suggested that the MIBG washout rate and the LVEF but not ECG parameters were significant and independent predictors of sudden cardiac death. Jacobson et al. [62] reported the results of a prospective MIBG imaging trial of 961 patients with heart failure recruited at 96 sites in North America and Europe. Their ADMIRE-HF study enrolled patients with New York Heart Association (NYHA) Class II and III heart failure and LVEF $\leq 35 \%$ and revealed that an $\mathrm{H} / \mathrm{M}$ ratio of $<1.6$ measured at $4 \mathrm{~h}$ after an MIBG administration provided prognostic data beyond that available from the LVEF, B-type natriuretic peptide assay, and NYHA class at the time of enrollment. Their multicenter prospective study confirmed the adrenergic neuronal functional parameter obtained by MIBG scan as an important parameter for predicting sudden death, independent of the commonly used LV functional parameters.

It is important to determine whether adrenergic function can predict the recovery of LV function or an improvement in outcome after treatment in patients with severe heart failure. There are a number of studies indicating that cardiac MIBG uptake improves after $\beta$-blocker or other therapy [63-71]. Suwa et al. [63] and Fukuoka et al. [64] both showed improvements of MIBG uptake and washout after $\beta$-blocker therapy in patients with dilated cardiomyopathy. The H/M ratio on the delayed images was a good predictor of the response to the $\beta$-blocker therapy [63]. Takeishi et al. [65] also reported improvement of MIBG uptake in relation to LVEF recovery after treatment with angiotensin-converting enzyme inhibitor in patients with
Fig. $3{ }^{11} \mathrm{C}$-hydroxyephedrine (HED) PET and MIBG SPECT of a normal subject. The HED PET obtained better-quality images in the myocardium as compared to the MIBG SPECT (Color figure online)

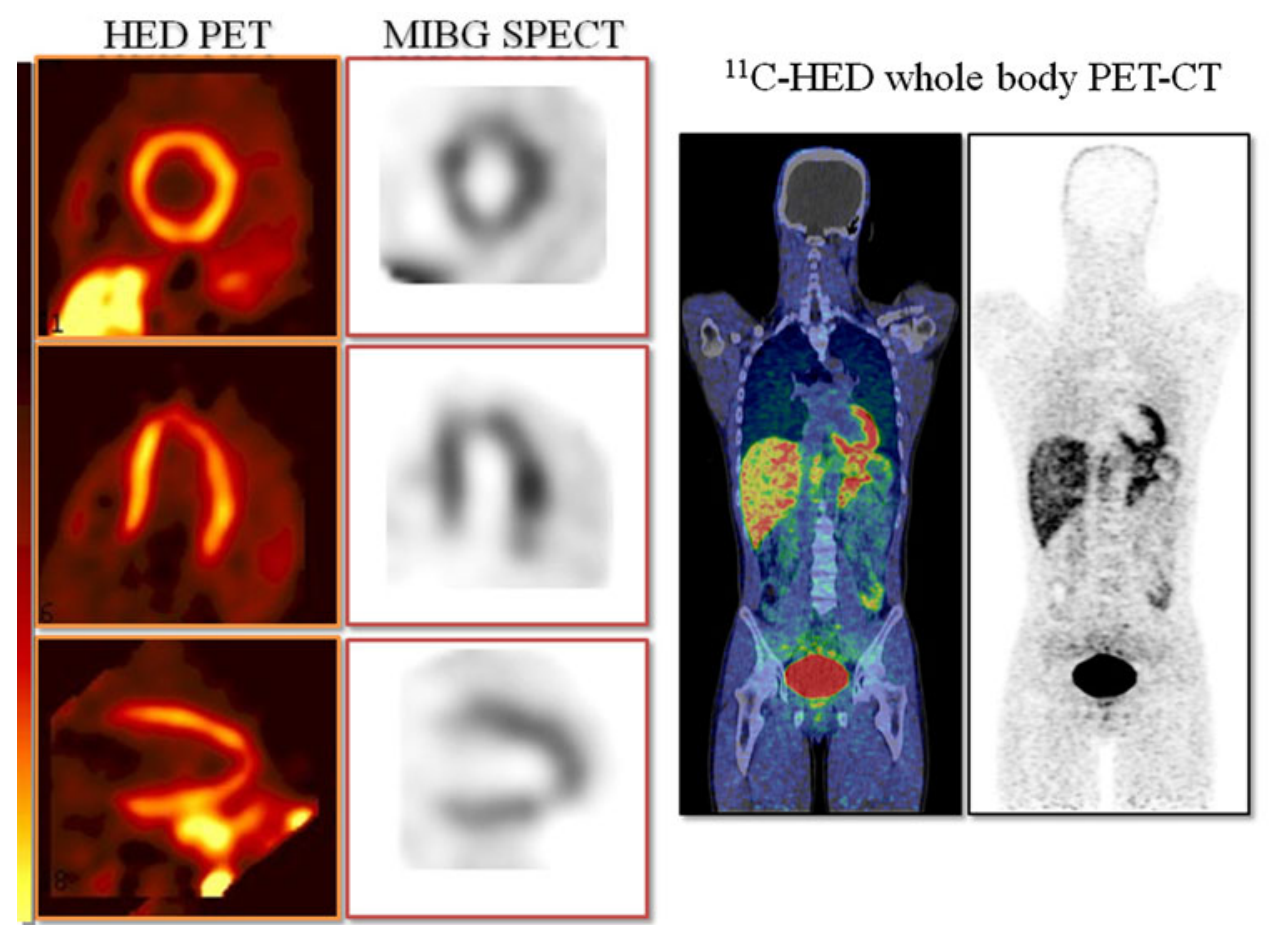



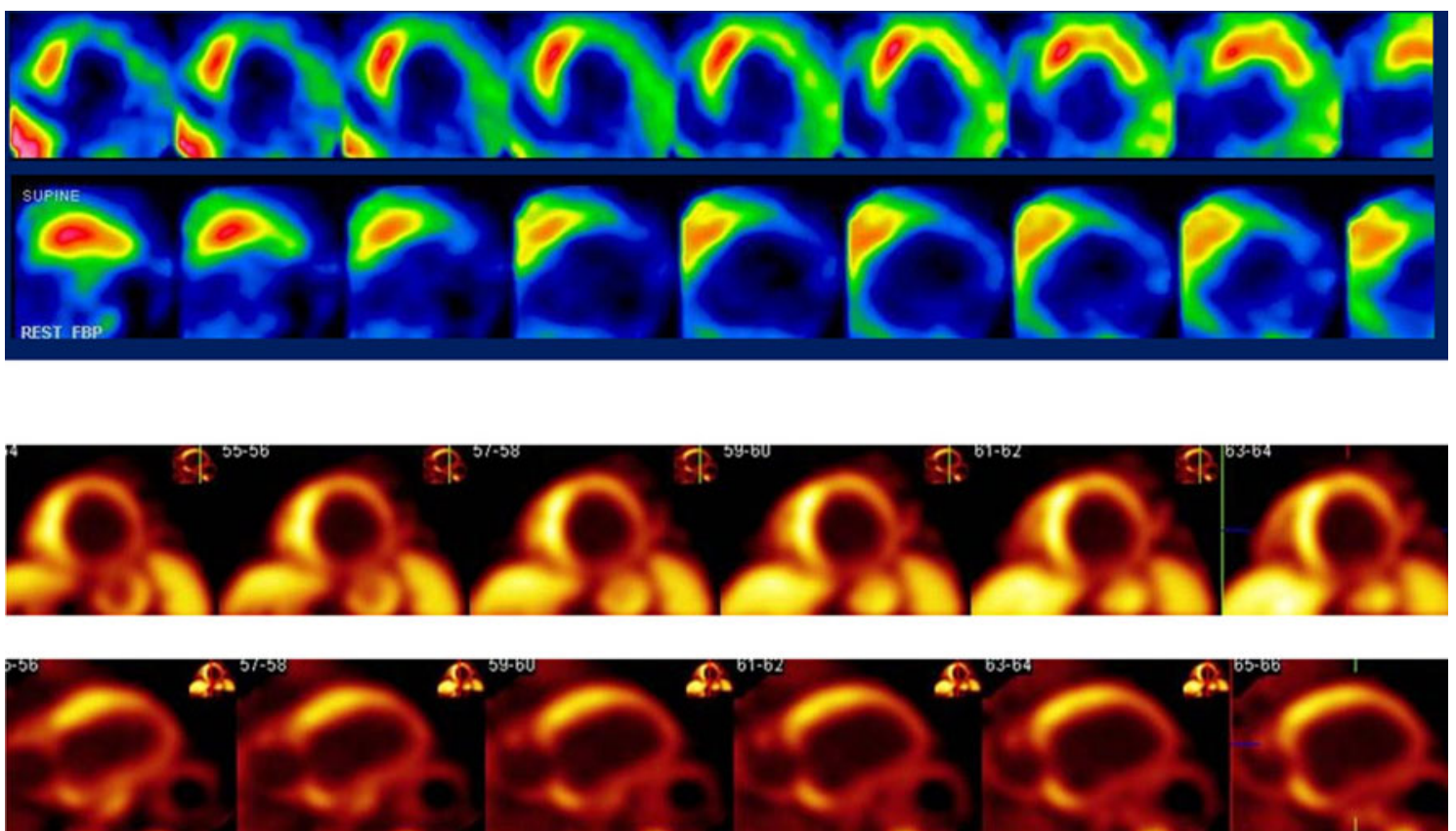

Fig. 4 A series of short-axis slices of MIBG SPECT and HED PET images of a patient with heart failure. A moderate reduction of tracer uptake is noted, particularly in the inferior and posterolateral regions (Color figure online)

Fig. 5 Coronal slice (left) and transaxial slice $(r i g h t)$ of PET images after the administration of ${ }^{11} \mathrm{C}$-CGP 12177 in a patient with idiopathic dilated cardiomyopathy (Color figure online)
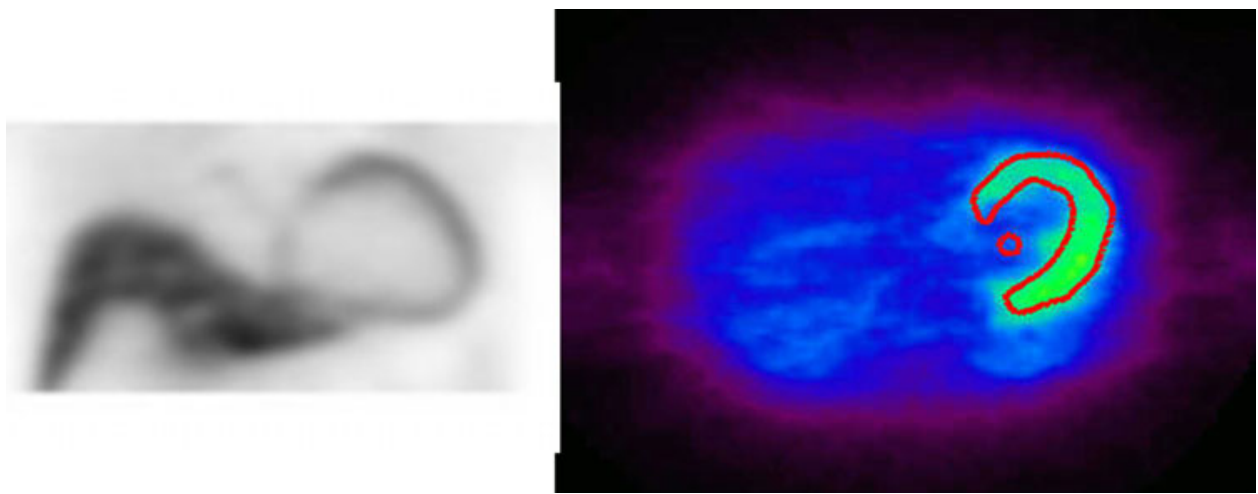

congestive heart failure. Gerson et al. [66] showed that the $\mathrm{H} / \mathrm{M}$ ratio improved significantly after carvedilol therapy, especially in patients with an $\mathrm{H} / \mathrm{M}$ ratio $<1.40$. Toyama et al. [67] reported favorable changes in symptoms, NYHA functional class, LV function, and the H/M ratio on MIBG imaging following treatment with the $\beta 1$-blocker metoprolol. Kasama et al. [68] observed a therapeutic effect of carvedilol on MIBG parameters and LV remodeling in patients with dilated cardiomyopathy. These data indicate that MIBG imaging may provide valuable information for the selection and optimization of treatment for congestive heart failure.

\section{Sympathetic neuronal imaging using PET}

PET offers great advantages in terms of higher spatial resolution and higher sensitivity with better quantification of tracer concentration compared to the commonly performed SPECT (Fig. 3). With the use of suitable tracer kinetic models, various molecular as well as functional parameters have been estimated in vivo. Various sympathetic neuronal PET tracers have been introduced which closely resemble the endogenous neurotransmitters, and these may allow more detailed analyses of neuronal signaling than MIBG can [72, 73].

${ }^{11} \mathrm{C}$-epinephrine is a radiolabeled true neurotransmitter, and the uptake and storage of this tracer resemble those of norepinephrine [74, 75]. ${ }^{11} \mathrm{C}$-phenylephrine is another PET tracer that is trapped in neuronal vesicles and metabolized by neuronal monoamine oxidase (MAO). Its kinetics may thus reflect $\mathrm{MAO}$ metabolism in addition to vesicular leakages [76].

${ }^{11} \mathrm{C}$-hydroxyephedrine (HED) is the most widely used PET tracer for cardiac neuronal imaging. It has high 
affinity for presynaptic neuronal catecholamine transporter (uptake 1) without being metabolized by MAO or catechol$O$-methyl-transferase [77, 78]. Denervation and reinnervation have been investigated using HED in various disorders, such as diabetes [79-81] and heart transplantation [82-84]. A study of patients with heart failure suggested that they had reduced HED uptake, particularly in the apical and inferoapical regions [85] (Fig. 4). In a study of heart failure patients before heart transplantation, the HED uptake in the myocardium closely correlated with uptake 1 and the norepinephrine content, confirming the value of HED imaging as a marker of sympathetic neuronal imaging [86].

A reduction of HED uptake may be a prognostic marker for heart failure patients. Pietilä et al. [87] described HED reduction as an independent risk factor, together with left ventricular end diastolic volume and peak $V \mathrm{O}_{2}$. An improvement in HED retention was observed after exercise training [88]. Another study compared HED retention with oxidative metabolism, but found no significant association in heart failure patients [89]. Most of these studies using HED seem to give findings similar to those that used MIBG imaging, suggesting autonomic function as an important new parameter for risk analysis and treatment monitoring, independent of other imaging and/or biomarkers.

Since HED PET provides higher spatial resolution and has a higher quantitative capability, it may hold promise for assessing patients with fatal arrhythmias. A global reduction in HED uptake in the myocardium was not observed in patients with Brugada syndrome [90] or those with long QT syndrome [91]. Since most of these studies are preliminary, more clinical studies with high-resolution PET are warranted.

\section{Adrenoreceptor imaging using PET}

Postsynaptic receptors transmit sympathetic signals to target cells. In particular, $\beta 1$ adrenoreceptor plays an important role in the regulation of myocardial cell function. Compared to the many presynaptic radioligands used for imaging, there are only a few radioligands that are suitable for postsynaptic neuron imaging and probing of neuronal functions. ${ }^{11} \mathrm{C}$-CGP 12177 is a non-selective hydrophilic $\beta$ receptor antagonist that provides high-quality PET images with low background activity (Fig. 5). We introduced a modified synthesis method which yielded higher specific activity of CGP 12177 [92]. CGP 12177 binds only to the functional receptors located at the cell surface. Two sequential PET images after an injection of high-specificactivity tracer followed by low-specific-activity tracer allow quantification of $\beta$-receptor density using a graphical analysis method [93]. Two other radiolabeled ligands were introduced for adrenoreceptor study: ${ }^{11} \mathrm{C}-\mathrm{CGP} 12388$ for $\beta$ -

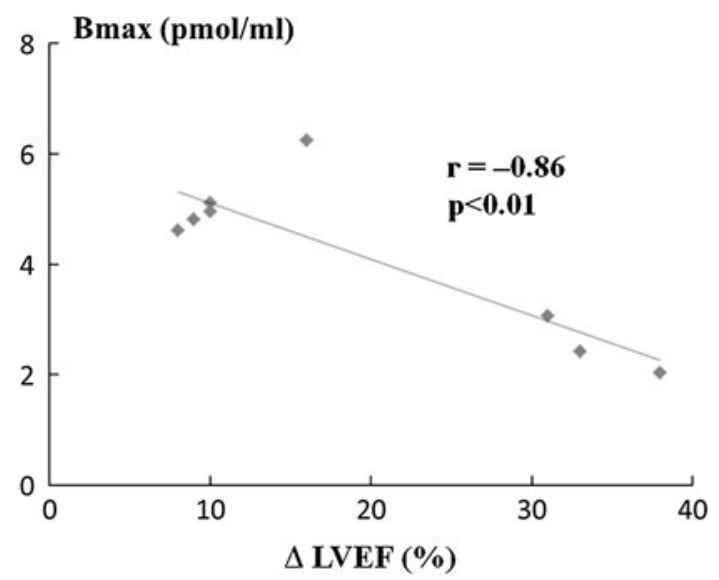

Fig. 6 Correlation between pretreatment $\beta$-receptor density estimated by ${ }^{11} \mathrm{C}$-CGP 12177 PET and the improvement in left ventricular ejection fraction $(\triangle \mathrm{LVEF})$ after long-term $\beta$-blocker treatment in patients with idiopathic dilated cardiomyopathy

receptor imaging [94], and ${ }^{11} \mathrm{C}$ GB-67 for $\alpha 1$-receptor imaging [95].

CGP 12177 has been used to demonstrate $\beta$-receptor downregulation in many heart failure patients [96-98]. Our data suggested that myocardial $\beta$-receptor density is inversely correlated with the MIBG washout rate and positively correlated with a delayed $\mathrm{H} / \mathrm{M}$ ratio, indicating that decreased $\beta$-receptor density was due to the increased presynaptic sympathetic tone [98]. These results suggest that myocardial $\beta$-receptor density may be directly associated with the beneficial response obtained by $\beta$-blocker treatment in heart failure patients. In addition, there was a close relationship between myocardial $\beta$-receptor density assessed by ${ }^{11} \mathrm{C}$-CGP 12177 PET and the improvement in left ventricular function after long-term $\beta$-blocker treatment in patients with idiopathic dilated cardiomyopathy (Fig. 6) [99]. We thus suggested that patients with advanced downregulation of myocardial $\beta$-receptor density have higher resting adrenergic drive and may derive greater benefits from the anti-adrenergic effects of $\beta$-blocker treatment. Further studies with many more patients with heart failure are warranted to test this finding.

\section{Conclusions}

Cardiovascular molecular imaging allows tissue characterization in myocardial disorders at molecular, subcellular, and cellular levels. It has potential for assessing the severity of heart failure and for monitoring treatment effects. ${ }^{123}$ I-labeled MIBG, as a marker of adrenergic neuron function, could play an important role in the risk stratification of heart failure patients. Presynaptic and postsynaptic neuron imaging using PET can potentially 
allow better quantifications of autonomic function. More clinical experience is needed to confirm the clinical impact of these imaging modalities for the management of heart failure patients.

Conflict of interest N. Tamaki, Y. Kuge and K. Yoshinaga declare that they have no conflict of interest.

Human and Animal Studies This article does not contain any studies with human or animal subjects performed by any of the authors.

Open Access This article is distributed under the terms of the Creative Commons Attribution License which permits any use, distribution, and reproduction in any medium, provided the original author(s) and the source are credited.

\section{References}

1. Heidenreich PA, Trogdon JG, Khavjou OA et al (2011) Forecasting the future of cardiovascular disease in the United States: a policy statement from the American Heart Association. Circulation 123:933-944

2. Ross H, Howlett J, Arnold JM et al (2006) Treating the right patient at the right time: access to heart failure care. Can J Cardiol 22:749-754

3. Roger VL, Westom SA, Redfield MM et al (2004) Trends in heart failure incidence and survival in a community-based population. JAMA 292:344-350

4. Owan TE, Hodge DO, Herges RM, Jacobsen SJ, Roger VL, Redfield MM (2006) Trends in prevalence and outcome of heart failure with preserved ejection fraction. $N$ Engl $J$ Med 355:251-259

5. Senni M, Tribouilloy CM, Rodeheffer RJ, Jacobsen SJ, Evans JM, Bailey KR et al (1998) Congestive heart failure in the community: a study of all incident cases in Olmsted County, Minnesota, in 1991. Circulation 98:2282-2289

6. Pfeffer MA, Braunwald E (1990) Ventricular remodeling after myocardial infarction. Experimental observations and clinical implications. Circulation 81:1161-1172

7. Pfeffer JM, Pfeffer MA, Fletcher PJ, Braunwald E (1991) Progressive ventricular remodeling in rat with myocardial infarction. Am J Physiol 260:H1406-H1414

8. Sutton MG, Sharpe N (2000) Left ventricular remodeling after myocardial infarction: pathophysiology and therapy. Circulation 101:2981-2988

9. Sano M, Minamino T, Toko H, Miyauchi H, Orimo M, Qin Y et al (2007) p53-induced inhibition of Hif-1 causes cardiac dysfunction during pressure overload. Nature 446:444-4448

10. Sosnovik DE, Nahrendorf M, Weissleder R (2007) Molecular magnetic resonance imaging in cardiovascular medicine. Circulation 115:2076-2086

11. Wu JC, Bengel FM, Gambhir SS (2007) Cardiovascular molecular imaging. Radiology 244:337-355

12. Sinusas AJ, Bengel FM, Nahrendorf M, Epstein FH, Wu JC, Villanueva FS, Fayad ZA, Gropler RJ (2008) Cardiovascular molecular imaging, part 1. Circ Cardiovasc Imaging 1:244-256

13. Bristow M, Ginsburg R, Minobe W, Cubicciotti RS, Sageman WS, Lurie K et al (1982) Decreased catecholamine sensitivity and beta-adrenergic-receptor density in failing human hearts. N Engl J Med 307:205-211
14. Mitrani RD, Klein LS, Miles WM et al (1993) Regional cardiac sympathetic denervation in patients with ventricular tachycardia in the absence of coronary artery disease. J Am Coll Cardiol 22:1344-1353

15. Randall WC, Armour JA, Geis WP, Lippencott DB (1972) Regional cardiac distribution of sympathetic nerves. Fed Proc 31:199-208

16. Shore PA, Cohn VH Jr, Highman B, Maling HM (1958) Distribution of norepinephrine in the heart. Nature 181:848-849

17. Zipes DP, Inoue H (1988) Autonomic neuronal control of cardiac excitable properties. In: Kulbertu HE, Franck G (eds) Neurocardiology. Futura, New York, pp 787-796

18. Eisenhofer G, Smolich JJ, Cox HS, Esler MD (1991) Neuronal reuptake of norepinephrine and production of dihydroxyphenylglycol by cardiac sympathetic nerves in the anesthetized dog. Circulation 84:1354-1363

19. Eisenhofer G, Esler MD, Meredith IT et al (1992) Sympathetic nervous function in human heart as assessed by cardiac spillovers of dihydroxyphenylglycol and norepinephrine. Circulation 85:1775-1785

20. Eisenhofer G, Friberg P, Rundqvist B et al (1996) Cardiac sympathetic nerve function in congestive heart failure. Circulation 93:1667-1676

21. Wieland DM, Brown LE, Rogers WL et al (1981) Myocardial imaging with a radioiodinated norepinephrine storage analog. J Nucl Med 22:22-31

22. Nakajo M, Shapiro B, Copp J et al (1983) The normal and abnormal distribution of the adrenomedullary imaging agent $\mathrm{m}$-[I-131]iodobenzylguanidine (I-131 MIBG) in man: evaluation by scintigraphy. J Nucl Med 24:672-682

23. Sisson JC, Shapiro B, Meyers L et al (1987) Metaiodobenzylguanidine to map scintigraphically the adrenergic nervous system in man. J Nucl Med 28:1625-1636

24. Dae MW, O'Connell JW, Botvinick EH et al (1989) Scintigraphic assessment of regional cardiac adrenergic innervation. Circulation 79:634-644

25. Sisson JC, Wieland DM, Scherman P et al (1987) Metaiodobenzylguanidine as an index of the adrenergic nervous system integrity and function. J Nucl Med 28:1620-1624

26. DeGrado TR, Zalutsky MR, Vaidyanathan G (1995) Uptake mechanism of meta-[123I] iodobenzylguanidine in isolated rat heart. Nucl Med Biol 22:1-12

27. Kaye MP, Tyce GM (1978) Norepinephrine uptake as an indicator of cardiac reinnervation in dogs. Am J Physiol 235:H289$\mathrm{H} 294$

28. Travin MI (2013) Cardiac autonomic imaging with SPECT tracers. J Nucl Cardiol 20:128-143

29. Kline RC, Swanson DP, Wieland DM, Thrall JH, Gross MD, Pitt B, Beierwaltes WH (1981) Myocardial imaging in man with I-123 meta-iodobenzylguanidine. J Nucl Med 22:129-132

30. Yamashina S, Yamazaki J (2007) Neuronal imaging using SPECT. Eur J Nucl Med Mol Imaging 34(Suppl 1):S62-S73

31. Okuda K, Nakajima K, Hosoya $T$, Ishikawa $T$, Konishi $T$, Matsubara K, Matsuo S, Kinuya S (2011) Semi-automated algorithm for calculating heart-to-mediastinum ratio in cardiac Iodine-123 MIBG imaging. J Nucl Cardiol 18:82-89

32. Matsuo S, Nakajima K, Yamashina S, Sakata K, Momose M, Hashimoto J, Kumita S, Kawano M, Okuda K (2009) Characterization of Japanese standards for myocardial sympathetic and metabolic imaging in comparison with perfusion imaging. Ann Nucl Med 23:517-522

33. Nakajima K (2010) Normal values for nuclear cardiology: Japanese databases for myocardial perfusion, fatty acid and sympathetic imaging and left ventricular function. Ann Nucl Med 24:125-135 
34. Nakajima K, Okuda K, Matsuo S, Yoshita M, Taki J, Yamada M, Kinuya S (2012) Standardization of metaiodobenzylguanidine heart to mediastinum ratio using a calibration phantom: effects of correction on normal databases and a multicentre study. Eur $\mathbf{J}$ Nucl Med Mol Imaging 39:113-119

35. Gill JS, Hunter GJ, Gane G, Camm AJ (1993) Heterogeneity of the human myocardial sympathetic innervation: in vivo demonstration by iodine 123-labeled meta-iodobenzylguanidine scintigraphy. Am Heart J 126:390-398

36. Tsuchimochi S, Tamaki N, Tadamura E, Kawamoto M, Fujita T, Yonekura Y, Konishi J (1995) Age and gender differences in normal myocardial adrenergic neuronal function evaluated by iodine-123-MIBG imaging. J Nucl Med 36:969-974

37. Schofer J, Spielmann R, Schuchert A, Weber K, Schlüter M (1988) Iodine-123 meta-iodobenzylguanidine scintigraphy: a noninvasive method to demonstrate myocardial adrenergic nervous system disintegrity in patients with idiopathic dilated cardiomyopathy. J Am Coll Cardiol 12:1252-1258

38. Henderson EB, Kahn JK, Corbett JR et al (1988) Abnormal I-123 metaiodobenzylguanidine myocardial washout and distribution may reflect myocardial adrenergic derangement in patients with congestive cardiomyopathy. Circulation 78:1192-1199

39. Glowniak JV, Turner FE, Gray LL et al (1989) Iodine-123 metaiodobenzylguanidine imaging of the heart with idiopathic congestive cardiomyopathy and cardiac transplants. J Nucl Med 30:1182-1191

40. Yamakado K, Takeda K, Kitano T et al (1992) Serial change of iodine-123 metaiodobenzylguanidine (MIBG) myocardial concentration in patients with dilated cardiomyopathy. Eur J Nucl Med 19:265-270

41. Merlet P, Benvenuti C, Moyse D et al (1999) Prognostic value of MIBG imaging in idiopathic dilated cardiomyopathy. J Nucl Med 40:917-923

42. Merlet P, Valette H, Dubois-Randé JL et al (1992) Prognostic value of cardiac metaiodobenzylguanidine imaging in patients with heart failure. J Nucl Med 33:471-477

43. Momose M, Kobayashi H, Iguchi N et al (1999) Comparison of parameters of 123I-MIBG scintigraphy for predicting prognosis in patients with dilated cardiomyopathy. Nucl Med Commun 20:529-535

44. Yamada T, Shimonagata T, Fukunami M et al (2003) Comparison of the prognostic value of cardiac iodine-123 metaiodobenzylguanidine imaging and heart rate variability in patients with chronic heart failure: a prospective study. J Am Coll Cardiol 41:231-238

45. Nakata T, Miyamoto K, Doi A, Sasao H, Wakabayashi T, Kobayashi H, Tsuchihashi K, Shimamoto K (1998) Cardiac death prediction and impaired cardiac sympathetic innervation assessed by MIBG in patients with failing and nonfailing hearts. J Nucl Cardiol 5:579-590

46. Nakata T, Wakabayashi T, Kyuma M, Takahashi T, Hashimoto A, Ogata $\mathrm{H}$ et al (2003) Prognostic implications of an initial loss of cardiac metaiodobenzylguanidine uptake and diabetes mellitus in patients with left ventricular dysfunction. J Card Fail 9:113-121

47. Kyuma M, Nakata T, Hashimoto A, Nagao K, Sasao H, Takahashi T, Tsuchihashi K, Shimamoto K (2004) Incremental prognostic implications of brain natriuretic peptide, cardiac sympathetic nerve innervation, and noncardiac disorders in patients with heart failure. J Nucl Med 45:155-163

48. Imamura Y, Fukuyama T, Mochizuki T, Miyagawa M, Watanabe K, Ehime MIBG Heart Failure Study Investigators (2001) Prognostic value of iodine-123-metaiodobenzylguanidine imaging and cardiac natriuretic peptide levels in patients with left ventricular dysfunction resulting from cardiomyopathy. Jpn Circ J 65:155-160
49. Fujimoto S, Amano H, Inoue A, Ishida S, Yamashina S, Yamashina H, Nakano H, Yamazaki J (2004) Usefulness of ${ }^{123} \mathrm{I}-$ metaiodobenzylguanidine myocardial scintigraphy in the prediction of cardiac events in patients with cardiomyopathy showing stabilization of symptoms or preserved cardiac function. Ann Nucl Med 18:591-598

50. Agostini D, Verberne HJ, Burchert W, Knuuti J, Povinec P, Sambuceti G, Unlu M, Estorch M, Banerjee G, Jacobson AF (2008) I-123-mIBG myocardial imaging for assessment of risk for a major cardiac event in heart failure patients: insights from a retrospective European multicenter study. Eur J Nucl Med Mol Imaging 35:535-546

51. Verberne HJ, Brewster LM, Somsen GA, van Eck-Smit BL (2008) Prognostic value of myocardial ${ }^{123}$ I-metaiodobenzylguanidine (MIBG) parameters in patients with heart failure: a systematic review. Eur Heart J 29:1147-1159

52. Kuwabara Y, Tamaki N, Nakata T, Yamashina S, Yamazaki J (2011) Determination of the survival rate in patients with congestive heart failure stratified by 123I-MIBG imaging: a metaanalysis from the studies performed in Japan. Ann Nucl Med 25:101-107

53. Podrid PJ, Fuchs T, Candinas R (1990) Role of the sympathetic nervous system in the genesis of ventricular arrhythmia. Circulation 82(2 Suppl):I103-I113

54. Zipes DP (1991) Sympathetic stimulation and arrhythmias. N Engl J Med 325:656-657

55. Arora R, Ferrick KJ, Nakata T et al (2003) I-123 MIBG imaging and heart rate variability analysis to predict the need for an implantable cardioverter defibrillator. J Nucl Cardiol 10:121-131

56. Nagahara D, Nakata T, Hashimoto A et al (2008) Predicting the need for an implantable cardioverter defibrillator using cardiac metaiodobenzylguanidine activity together with plasma natriuretic peptide concentration or left ventricular function. J Nucl Med 49:225-233

57. Nishisato K, Hashimoto A, Nakata $T$, Doi $T$, Yamamoto $H$, Nagahara D (2010) Impaired cardiac sympathetic innervation and myocardial perfusion are related to lethal arrhythmia: quantification of cardiac tracers in patients with ICDs. J Nucl Med 51:1241-1249

58. Kasama S, Toyama T, Sumino H, Nakazawa M, Matsumoto N, Sato Y et al (2008) Prognostic value of serial cardiac ${ }^{123}$ I-MIBG imaging in patients with stabilized chronic heart failure and reduced left ventricular ejection fraction. J Nucl Med 49:907-914

59. Bax JJ, Kraft O, Buxton AE et al (2008) ${ }^{123}$ I-MIBG scintigraphy to predict inducibility of ventricular arrhythmias on cardiac electrophysiology testing: a prospective multicenter pilot study. Circ Cardiovasc Imaging 1:131-140

60. Boogers MJ, Borleffs CJ, Henneman MM, van Bommel RJ, van Ramshorst J, Boersma E et al (2010) Cardiac sympathetic denervation assessed with 123-iodine metaiodobenzylguanidine imaging predicts ventricular arrhythmias in implantable cardioverter defibrillator patients. J Am Coll Cardiol 55:2769-2777

61. Tamaki S, Yamada T, Okuyama Y, Morita T, Sanada S, Tsukamoto Y, Masuda M, Okuda K, Iwasaki Y, Yasui T, Hori M, Fukunami M (2009) Cardiac iodine-123 metaiodobenzylguanidine imaging predicts sudden cardiac death independently of left ventricular ejection fraction in patients with chronic heart failure and left ventricular systolic dysfunction: results from a comparative study with signal-averaged electrocardiogram, heart rate variability, and QT dispersion. J Am Coll Cardiol 53:426-435

62. Jacobson AF, Senior R, Cerqueira MD, Wong ND, Thomas GS, Lopez VA, Agostini D, Weiland F, Chandna H, Narula J, ADMIRE-HF Investigators (2010) Myocardial iodine-123 metaiodobenzylguanidine imaging and cardiac events in heart failure. Results of the prospective ADMIRE-HF (AdreView Myocardial 
Imaging for Risk Evaluation in Heart Failure) study. J Am Coll Cardiol 55:2212-2221

63. Suwa M, Otake Y, Moriguchi A et al (1997) Iodine-123 metaiodobenzylguanidine myocardial scintigraphy for prediction of response to beta-blocker therapy in patients with dilated cardiomyopathy. Am Heart J 133:353-358

64. Fukuoka S, Hayashida K, Hirose Y et al (1997) Use of iodine-123 metaiodobenzylguanidine myocardial imaging to predict the effectiveness of beta -blocker therapy in patients with dilated cardiomyopathy. Eur J Nucl Med 24:523-529

65. Takeishi Y, Atsumi H, Fujiwara S, Takahashi K, Tomoike H (1997) ACE inhibition reduces cardiac iodine-123-MIBG release in heart failure. J Nucl Med 38:1085-1089

66. Gerson MC, Craft LL, McGuire N, Suresh DP, Abraham WT, Wagoner LE (2002) Carvedilol improves left ventricular function in heart failure with idiopathic cardiomyopathy and a wide range of sympathetic nervous system function as measured by iodine123 metaiodobenzylguanidine. J Nucl Cardiol 9:608-615

67. Toyama T, Aihara Y, Iwasaki T, Hasegawa A, Suzuki T, Nagai R et al (1999) Cardiac sympathetic activity estimated by 123IMIBG myocardial imaging in patients with dilated cardiomyopathy after beta-blocker or angiotensin-converting enzyme inhibitor therapy. J Nucl Med 40:217-223

68. Kasama S, Toyama T, Hatori T, Sumino H, Kumakura H, Takayama Y et al (2007) Evaluation of cardiac sympathetic nerve activity and left ventricular remodelling in patients with dilated cardiomyopathy on the treatment containing carvedilol. Eur Heart J 28:989-995

69. Agostini D, Belin A, Amar MH, Darlas Y, Hamon M, Grollier G et al (2000) Improvement of cardiac neuronal function after carvedilol treatment in dilated cardiomyopathy: a 123I-MIBG scintigraphic study. J Nucl Med 41:845-851

70. Cohen-Solal A, Rouzet F, Berdeaux A, Le Guludec D, Abergel E, Syrota A, Merlet P (2005) Effects of carvedilol on myocardial sympathetic innervation in patients with chronic heart failure. J Nucl Med 46:1796-1803

71. Fujimoto $S$, Inoue $A$, Hisatake $S$, Yamashina $S$, Yamashina $H$, Nakano H et al (2004) Usefulness of 123I-metaiodobenzylduanidine myocardial scintigraphy for predicting the effectiveness of beta-blockers in patients with dilated cardiomyopathy from the standpoint of long-term prognosis. Eur J Nucl Med Mol Imaging 31:1356-1361

72. Langer O, Halldin C (2002) PET and SPET tracers for mapping the cardiac nervous system. Eur J Nucl Med Mol Imaging 29:416-434

73. Lautamäki R, Tipre D, Bengel FM (2007) Cardiac sympathetic neuronal imaging using PET. Eur J Nucl Med Mol Imaging 34(Suppl 1):S74-S85

74. Nguyen NT, DeGrado TR, Chakraborty P, Wieland DM, Schwaiger M (1997) Myocardial kinetics of carbon-11-epinephrine in the isolated working rat heart. J Nucl Med 38:780-785

75. Münch G, Nguyen NT, Nekolla S et al (2000) Evaluation of sympathetic nerve terminals with [(11)C]epinephrine and [(11)C]hydroxyephedrine and positron emission tomography. Circulation 101:516-523

76. Raffel DM, Wieland DM (1999) Influence of vesicular storage and monoamine oxidase activity on [11C]phenylephrine kinetics; studies in isolated rat heart. J Nucl Med 40:323-330

77. DeGrado TR, Hutchins GD, Toorongian SA, Wieland DM, Schwaiger M (1993) Myocardial kinetics of carbon-11-metahydroxyephedrine; retention mechanisms and effects of norepinephrine. J Nucl Med 34:1287-1293

78. Schwaiger M, Hutchins GD, Kalff V et al (1991) Evidence for regional catecholamine uptake and storage sites in the transplanted human heart by positron emission tomography. J Clin Invest 87:1681-1690
79. Stevens MJ, Raffel DM, Allman KC et al (1998) Cardiac sympathetic dysinnervation in diabetes: implications for enhanced cardiovascular risk. Circulation 98:961-968

80. Rimoldi OE, Drake-Holland AJ, Noble MI, Camici PG (2007) Basal and hyperaemic myocardial blood flow in regionally denervated canine hearts: an in vivo study with positron emission tomography. Eur J Nucl Med Mol Imaging 34:197-205

81. Stevens MJ, Dayanikli F, Raffel DM et al (1998) Scintigraphic assessment of regionalized defects in myocardial sympathetic innervation and blood flow regulation in diabetic patients with autonomic neuropathy. J Am Coll Cardiol 31:1575-1584

82. DiCarli MF, Tobes MC, Mangner T et al (1997) Effects of cardiac sympathetic innervation in coronary blood flow. N Engl J Med 336:1208-1215

83. Bengel FM, Ueberfuhr P, Ziegler SI et al (1999) Serial assessment of sympathetic reinnervation after orthotopic heart transplantation. A longitudinal study using PET and C-11 hydroxyephedrine. Circulation 99:1866-1871

84. Bengel FM, Ueberfuhr P, Schiepel N, Nekolla SG, Reichart B, Schwaiger M (2001) Effect of sympathetic reinnervation on cardiac performance after heart transplantation. N Engl J Med 345:731-738

85. Hartmann F, Ziegler S, Nekolla S et al (1999) Regional patterns of myocardial sympathetic denervation in dilated cardiomyopathy: an analysis using carbon-11 hydroxyephedrine and positron emission tomography. Heart 81:262-270

86. Ungerer M, Hartmann F, Karoglan M et al (1998) Regional in vivo and in vitro characterization of autonomic innervation in cardiomyopathic human heart. Circulation 97:174-180

87. Pietilä M, Malminiemi K, Ukkonen $\mathrm{H}$ et al (2001) Reduced myocardial carbon-11 hydroxyephedrine retention is associated with poor prognosis in chronic heart failure. Eur J Nucl Med 28:373-376

88. Pietilä M, Malminiemi K, Vesalainen R et al (2002) Exercise training in chronic heart failure: beneficial effects on cardiac (11)C-hydroxyephedrine PET, autonomic nervous control, and ventricular repolarization. J Nucl Med 43:773-779

89. Bengel FM, Permanetter B, Ungerer M, Nekolla SG, Schwaiger M (2002) Alteration of the sympathetic nervous system and metabolic performance of the cardiomyopathic heart. Eur J Nucl Med Mol Imaging 29:198-202

90. Kies P, Wichter T, Schäfers M et al (2004) Abnormal myocardial presynaptic norepinephrine recycling in patients with Brugada syndrome. Circulation 110:3017-3022

91. Calkins H, Lehmann MH, Allman K, Wieland D, Schwaiger M (1993) Scintigraphic pattern of regional sympathetic innervation in patients with familiar long QT syndrome using positron emission tomography. Circulation 87:1616-1621

92. Nishijima K, Kuge Y, Seki K et al (2004) Preparation and pharmaceutical evaluation for clinical application of high specific activity S-(-) $\left[{ }^{11} \mathrm{C}\right] \mathrm{CGP}-12177$, a radioligand for beta-adrenoreceptors. Nucl Med Commun 25:845-849

93. Delforge J, Syrota A, Lançon JP et al (1991) Cardiac betaadrenergic receptor density measured in vivo using PET, CGP 12177, and a new graphical method. J Nucl Med 32:739-748

94. Elsinga PH, Doze $\mathrm{P}$, van Waarde $A$ et al (2001) Imaging of betaadrenoceptors in the human thorax using (s)- $\left[{ }^{11} \mathrm{C}\right] \mathrm{CGP} 12388$ and positron emission tomography. Eur J Pharmacol 433:173-176

95. Law MP, Osman S, Pike VW et al (2000) Evaluation of $\left[{ }^{11} \mathrm{C}\right]$ GP67, a novel radioligand for imaging myocardial alpha 1 -adrenoceptors with positron emission tomography. Eur J Nucl Med 27:7-17

96. Merlet P, Delforge J, Syrota A et al (1993) Positron emission tomography with ${ }^{11} \mathrm{C}$ CGP-12177 to assess beta-adrenergic receptor concentration in idiopathic dilated cardiomyopathy. Circulation 87:1169-1178 
97. Spyrou N, Rosen SD, Fath-Ordoubadi F et al (2002) Myocardial beta-adrenoreceptor density one month after acute myocardial infarction predicts left ventricular volumes at six months. J Am Coll Cardiol 40:1216-1224

98. Tsukamoto T, Morita K, Naya M et al (2007) Decreased myocardial beta-adrenergic receptor density in relation to increased sympathetic tone in patients with nonischemic cardiomyopathy. J Nucl Med 48:1777-1782
99. Naya M, Tsukamoto T, Morita K, Katoh C, Nishijima K, Komatsu H, Yamada S, Kuge Y, Tamaki N, Tsutsui H (2009) Myocardial beta-adrenergic receptor density assessed by ${ }^{11} \mathrm{C}$ CGP12177 PET predicts improvement of cardiac function after carvedilol treatment in patients with idiopathic dilated cardiomyopathy. J Nucl Med 50:220-225 